\title{
Effectiveness analysis of antipsychotics in schizophrenia using psychometric scales: an observational study
}

\author{
Ratna Agrawal $^{1}$, Bhabagrahi Rath ${ }^{2 *}$, Rajni Kant Shukla ${ }^{3}$, Sabita Mohapatra ${ }^{4}$
}

\author{
${ }^{1}$ Department of Pharmacology, Late Baliram Kashyap Memorial Government Medical College, Dimrapal, Jagdalpur, \\ Chhattisgarh, India \\ ${ }^{2}$ Department of Pharmacology, ${ }^{3}$ Department of Psychiatry, V.S.S. Institute of Medical Sciences and Research, Burla, \\ Sambalpur, Odisha, India \\ ${ }^{4}$ Department of Pharmacology, SCB Medical College and Hospital, Cuttack, Odisha, India
}

Received: 25 November 2019

Accepted: 07 January 2020

*Correspondence:

Dr. Bhabagrahi Rath,

Email: ratna.arang@gmail.com

Copyright: (C) the author(s), publisher and licensee Medip Academy. This is an open-access article distributed under the terms of the Creative Commons Attribution Non-Commercial License, which permits unrestricted non-commercial use, distribution, and reproduction in any medium, provided the original work is properly cited.

\begin{abstract}
Background: Schizophrenia is a commonest and one of the well known psychiatric disorders. Life expectancy of a patient with schizophrenia may be 20 to 30 years shorter than the general population. Long term antipsychotic therapy is usually required for the management of schizophrenia. It is not currently possible to predict which antipsychotic may be optimal for a given patient because there are still many debates about effectiveness and efficacy of atypical drugs over first generation antipsychotics. So, our aim is to assess the effectiveness of various antipsychotics by using various psychometric scales, which will be helpful to bring out better treatment options for schizophrenia patients.

Methods: This was an observational questionnaire based study, conducted on patients of inpatient and outpatient Department of Psychiatry and Department of Pharmacology at VIMSAR, Burla, for a period of 24 months (September 2015 to August 2017). Patients of schizophrenia aged 18 years or above were subjected to clinical global impression - severity scale (CGI-S) and clinical global impression - improvement scale (CGI-I) questionnaire after taking informed consent. Then scores were calculated using non parametric test with Graph pad Prism version 6.0.

Results: Out of the 90 cases, majority (60) of patients belonged to the middle ( 25 to 45 yrs) age group followed by 20 younger $(<25 \mathrm{yrs})$ age group and rest 10 were elderly $(>45 \mathrm{yrs})$ patients. Both scales showed significant improvement with atypical antipsychotics as compared to first generation antipsychotics.

Conclusions: Based on these findings, we can conclude that atypical antipsychotics are more effective than first generation antipsychotics. But further studies are needed to assist clinicians in making optimum treatment decisions.
\end{abstract}

Keywords: Antipsychotics, CGI-I scale, CGI-S scale, Schizophrenia

\section{INTRODUCTION}

Schizophrenia is a chronic debilitating mental illness with a lifetime prevalence of $1 \%$, characterized by positive symptoms, disorganization, negative symptoms, cognitive symptoms, mood and motor symptoms, with the types and severity of symptoms differing among patients and over the course of illness. ${ }^{1,2}$ Relapses are associated with adverse short and long term sequelae and remissions are generally incomplete. Long term antipsychotic therapy is cornerstone of schizophrenia management. ${ }^{3}$ First generation (typical) or conventional antipsychotic agents, such as fluphenazine and haloperidol have been used for decades to treat patients with schizophrenia and are effective in reducing many symptoms of disease. However events associated with these drugs, including the risk of extrapyramidal symptoms (dystonia, parkinsonism and akathisia) and 
tardive dyskinesia at therapeutic doses limit their use in some patients, so the treatment thus include treatment of acute psychotic exacerbations, relapse prevention, minimization of adverse effects and amelioration of broad range of symptoms including positive, negative, cognitive and mood symptoms. ${ }^{4}$ Cognitive dysfunction is the strongest predictor of functional impairment among schizophrenia patients, yet negative symptoms and cognitive deficits show limited improvement with antipsychotic treatment.

There are around 65 antipsychotic medications utilized across the world. They are classified into two groups First generation antipsychotics and Second generation (atypical) antipsychotics. Antipsychotics are effective in both treating the acute psychotic episode and preventing relapses. $^{5}$ Both First generation antipsychotics and second-generation antipsychotics are effective in reducing positive and disorganization symptoms but are only minimally effective for negative and cognitive symptoms, which contribute significantly to the disability associated with schizophrenia. ${ }^{6}$

Various previously available studies states that there are no consistent differences in efficacy among antipsychotic agents, except for the superior efficacy of clozapine in treating positive symptoms and disorganization in otherwise antipsychotic refractory schizophrenia patients. $^{7,8}$

Although, second generation antipsychotics were all initially believed to be more efficacious and tolerable than first generation antipsychotics, results of large scale studies (such as the clinical antipsychotic trials of intervention effectiveness (CATIE)) indicate that second generation antipsychotics are no more efficacious than first generation antipsychotics, in contrast to their efficacy in treating disorganization and positive symptoms, antipsychotics are less effective in reducing negative, cognitive and mood symptoms. Therefore, it is not currently possible to predict which antipsychotic may be optimal for a given patient.

There are still many debates about supremacy of other atypical drugs over earlier medication. Decision about antipsychotic therapy therefore often entail a trial onerror process involving careful monitoring of response and adverse effects, an ongoing risk benefit assessment, and judicious switching if necessary. A number of simple scales exist to facilitate such measurements. So, to find out optimal therapy for schizophrenia, this study has been designed to investigate and compare the effectiveness of various antipsychotics with different pharmacological and clinical profile in the course of schizophrenia using various psychometric scales.

\section{METHODS}

After obtaining the Institutional Ethics Committee clearance and informed consent from participants the study has been conducted on the patients of inpatient and outpatient Department of Psychiatry and Department of Pharmacology at V. S. S. Institute of Medical Sciences \& Research, Burla from September 2015 to August 2017.

Prospective, observational and questionnaire-based study was designed with sample size of ninety patients suffering from schizophrenia.

Selection of cases: Convenience sampling.

\section{Inclusion criteria:}

Patients of schizophrenia aged 18 years or older, diagnosed according to the Diagnostic and Statistical Manual of Mental Disorders, Fifth Edition, and provided written informed consent were included.

\section{Exclusion criteria}

Patients who were at imminent risk of injury to themselves or others, who had a known hypersensitivity to drugs, or who had been treated with investigational agents within the previous 30 days were not eligible for enrollment. Women of childbearing potential who were not using an adequate method of contraception and women who were pregnant or breast feeding were also not eligible for participation.

\section{Method of study}

This was a 24-month, prospective, observational study in patients with schizophrenia who were initiated on various typical and atypical antipsychotics. Physicians were allowed to change treatment during the study as clinically warranted. Data has been collected at baseline and subsequently every 6 months up to 24 months for clinical global impression (CGI) scales. ${ }^{9}$

\section{Statistical analysis}

All the scores have been evaluated using Graph pad prism version 6.0 using non- parametric scales. $P$ value $<0.05$ was kept statistically significant.

\section{RESULTS}

Overall 90 patients suffering from schizophrenia, at different stages of disease, treated with different type of antipsychotic agents were included in the study to observe the effectiveness of various antipsychotics.

\section{Demographic profile of patients}

Out of the 90 cases, majority of patients belonged to the middle (25 to $45 \mathrm{yrs}$ ) age group $(60(66.7 \%))$, followed by younger $(<25$ yrs $)$ age group $(20(22.2 \%))$ and rest were elderly (>45 yrs) patients $(10(11.1 \%))$ as shown in Table 1. 
Table 1: Age distribution of schizophrenia patients.

\begin{tabular}{|ll|}
\hline Age (in years) & No. of cases $(\%)$ \\
\hline $\mathbf{2 5}$ & $20(22.2)$ \\
\hline $\mathbf{2 5}-\mathbf{4 5}$ & $60(66.7)$ \\
\hline $\mathbf{4 5}$ & $10(11.1)$ \\
\hline
\end{tabular}

Out of 90 cases, $60(66.7 \%)$ were males and $30(33.3 \%)$ were females as presented in Table 2 .

Table 2: Sex distribution of schizophrenia patients.

\begin{tabular}{|ll|}
\hline Gender & No. of cases $(\%)$ \\
\hline Males & $60(66.7)$ \\
\hline Females & $30(33.3)$ \\
\hline
\end{tabular}

Educational status of schizophrenia patients was as follows: out of 90 cases, $30(33.3 \%)$ patients were illiterate, $6(6.7 \%)$ patients had studied below $8^{\text {th }}$ standard, $44(48.9 \%)$ had studied above $8^{\text {th }}$ standard but below $12^{\text {th }}$ standard and only $10(11.1 \%)$ patients had studied above 12th standard as depicted in Figure 1.

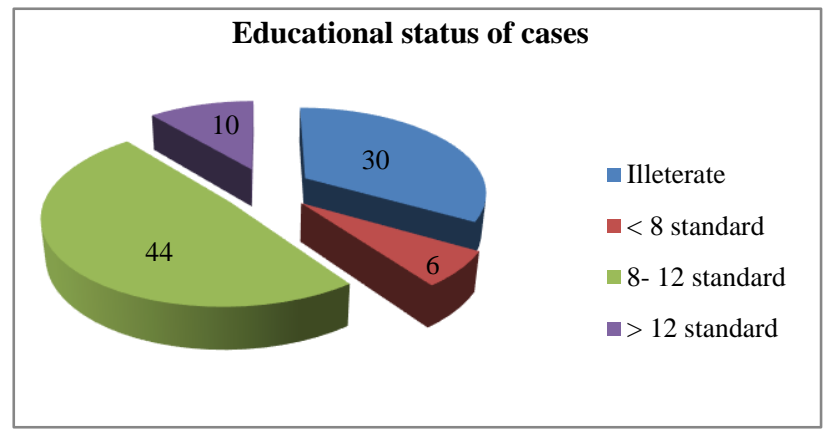

Figure 1: Educational status of schizophrenia patients.

The antipsychotics prescribed during last one year were trifluoperazine and chlorpromazine ( $1^{\text {st }}$ generation antipsychotics) and olanzapine, risperidone, clozapine and amisulpiride (atypical antipsychotics) as shown in Table 3.
Table 3: Antipsychotics usage during last one year.

\begin{tabular}{|ll|}
\hline Type of antipsychotic & No. of cases $(\%)$ \\
\hline Olanzapine & $20(22.2)$ \\
\hline Risperidone & $10(11.1)$ \\
\hline Amisulpride & - \\
\hline Clozapine & $2(2.2)$ \\
\hline Trifluoperazine & $32(35.6)$ \\
\hline Chlorpromazine & $26(28.9)$ \\
\hline
\end{tabular}

Other than antipsychotics, various other medications were used in order to minimize side effects of antipsychotics and to treat the other symptoms of disease. The most commonly used agents were anticholinergics (trihexyphenidyl) (46 (51.1\%)), benzodiazepines (clonazepam, alprazolam, nitrazepam, lorazepam) (70 (77.78\%)), antiemetics (domperidone) (26 (28.89\%)), antihistaminics (promethazine) (34 (37.78\%)), proton pump inhibitors (pantoprazole, omeprazole) (26 (28.89\%)), mood stabilizers (valproate) (10 (11.11\%)), Co-enzyme Q-20 (12 (13.33\%)) and multivitamins $(22(24.44 \%))$ as depicted in Figure 2.

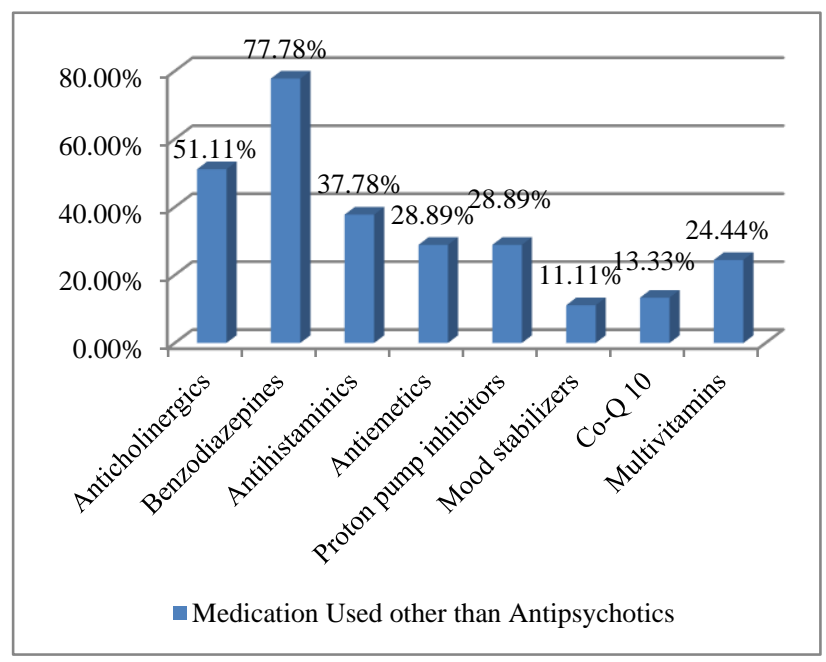

Figure 2: Medications used other than antipsychotics.

Table 4: CGI- S and CGI- I scale scores during treatment with first generation and atypical antipsychotics on 6 month duration.

\begin{tabular}{|llll|} 
Scales & $\begin{array}{l}\text { Total score with first generation } \\
\text { antipsychotics after } 6 \text { month } \\
\text { duration }(\text { Mean } \pm \text { SEM) }\end{array}$ & $\begin{array}{l}\text { Total score with atypical } \\
\text { antipsychotics after } 6 \text { month } \\
\text { duration (Mean } \pm \text { SEM) }\end{array}$ & $\begin{array}{l}\text { Level of } \\
\text { significance }\end{array}$ \\
\hline CGI- S Scale & $3.5 \pm 0.26$ & $2.5 \pm 0.18$ & $0.0156^{*}$ \\
\hline CGI- I Scale & $2.63 \pm 0.18$ & $1.88 \pm 0.13$ & $0.03^{*}$ \\
\hline
\end{tabular}

$* \mathrm{p}<0.05=$ statistically significant, clinical global impression - severity scale (CGI-S) and clinical global impression - improvement scale (CGI-I).

\section{Result of assessment of schizophrenia patients by various scales (CGI-S and CGI-I)}

At baseline, out of 90 patients 58 patients were receiving first generation antipsychotics and rest 32 patients were taking atypical antipsychotics. At the end of 6 months, 16 patients out of 58 who were receiving first generation antipsychotics were switched to atypical antipsychotics and 4 patients out of 32 patients who were taking atypical antipsychotics were switched to first generation drugs due to side effects, so total number of patients in first generation group was 46 and in atypical group were 44 . 
At the end of 12 months, 30 patients out of remaining 46 patients (first generation group) were switched to atypical antipsychotics, so atypical group contained 74 patients and first-generation group contained 16 patients. After that no change had been made in the treatment of patients, the same treatment was continued till the completion of the study period.
The comparison of effectiveness of first generation and atypical antipsychotics was made by using CGI-S scale which measures severity of disease, CGI-I scale which measures improvement in disease condition at 6,12 and 18 months by using non parametric, paired t-test (Wilcoxan signed rank test).

Table 5: CGI- S and CGI- I scale scores during treatment with first generation and atypical antipsychotics after 12 month duration.

\begin{tabular}{|llll|} 
Scales & $\begin{array}{l}\text { Total score with first generation } \\
\text { antipsychotics after } \mathbf{1 2} \text { month } \\
\text { duration }(\text { Mean } \pm \text { SEM) }\end{array}$ & $\begin{array}{l}\text { Total score with atypical } \\
\text { antipsychotics after 12 month } \\
\text { duration (Mean } \pm \text { SEM) }\end{array}$ & $\begin{array}{l}\text { Level of } \\
\text { significance }\end{array}$ \\
\hline CGI- S scale & $2.87 \pm 0.35$ & $2 \pm 0.38$ & $0.0002^{* * *}$ \\
\hline CGI- I scale & $2.06 \pm 0.26$ & $1.20 \pm 0.41$ & $0.0002^{* * *}$ \\
\hline
\end{tabular}

$* \mathrm{p}<0.05=$ Statistically significant, $* * \mathrm{p}<0.01=$ Highly Significant, $* * * \mathrm{p}<0.001=$ very highly significant

Both scales showed significant improvement with atypical antipsychotics as compared to first generation antipsychotics as shown in Table 4 and Table 5.

\section{DISCUSSION}

This prospective observational study intended to compare the effectiveness of typical and atypical antipsychotics in our tertiary care hospital provided the above mentioned data which mostly correlates with previous research articles.

The age group for schizophrenia in present study was same as the study conducted by Cortesi et al. ${ }^{10}$ The peak age of onset of schizophrenia is $10-35$ years. ${ }^{11}$ The onset may be abrupt or insidious, but majority of people manifest a slow and gradual development. ${ }^{12}$ Gender distribution revealed male predominance in this study. This corroborates with the study conducted by Johnson et al, Suresh et al and Kua et al. ${ }^{13-15}$

Educational status of schizophrenia patients was poor as $33.3 \%$ patients were illiterate, $6.7 \%$ patients had studied below $8^{\text {th }}$ standard, $48.9 \%$ patients had studied above $8^{\text {th }}$ standard but below $12^{\text {th }}$ standard and only $11.1 \%$ patients had studied above $12^{\text {th }}$ standard. Result of this study is similar to the study conducted by Cortesi et al who also had reported poor educational status among schizophrenia patients. ${ }^{10}$ Educational status of schizophrenia patient is an important factor for prognosis. ${ }^{12}$ In general, it is said that poor educational status is associated with poor prognosis. $^{12}$

The types of antipsychotics prescribed in last one-year duration in present study were trifluoperazine and chlorpromazine (first generation) and olanzapine, risperidone, clozapine and amisulpiride (atypical). On retrospectively observing the patients record, it was evident that haloperidol has been prescribed to every patients on their $1^{\text {st }}$ episodes but soon were switched to other typical or atypical antipsychotics because of extrapyramidal side effects. Other studies, in contrast to this study studied that the newer antipsychotics like aripiprazole, ziprasidone, quetiapine etc were most commonly prescribed. ${ }^{16,17}$ But, as our study is a government hospital based study, prescription of free drugs is mandatory for the clinicians and also, the other reason for non - prescription of newer antipsychotics was their high cost and patients in our study belonged to low socio-economic status.

In order to minimize side effects of antipsychotics and to treat the other symptoms of disease, various other medications were used. The proportion of use of anticholinergics, benzodiazepines, mood stabilizers and anti-histaminics were almost similar to study conducted by McCue et al. ${ }^{18}$ But prescription of PPIs, vitamins and enzymes were additional in the present study.

Result of this study is in corroboration with the study conducted by Macfadden et al, who found that patients with schizophrenia had reduced illness severity (as measured by CGI-S scale) and improved clinician rated functioning with atypical antipsychotics (as measured by level of functioning scale, global assessment of functioning scale and personal and social performance scale) after 3 months of treatment. ${ }^{19}$ Results of the study conducted by Ravanic et al were also similar to this study i.e. atypical antipsychotics, in long term (five years) showed better effectiveness in chronic schizophrenia with positive and negative symptoms than typical antipsychotics as per scores of psychometric instruments likegeneral well-being scale, positive and negative syndrome scale and CGI. ${ }^{17}$

\section{CONCLUSION}

Overall, these results may contribute to clarify the existing controversial data available regarding effectiveness of first generation and atypical antipsychotics. Based on these findings, it can be said that atypical antipsychotics are more effective than first generation antipsychotics in terms of severity reduction and improvement in symptoms. But, because of 
availability of many newer antipsychotics and controversial knowledge about their effectiveness, more studies involving other antipsychotics, employing other scales and including patients of diverse socio-economic status are needed to get still deeper insight into the effectiveness of various antipsychotics in the management of schizophrenia.

\section{ACKNOWLEDGEMENTS}

Authors are thankful to Head of the Department, Psychiatry V.S.S Institute of Medical Science and Research, Burla, Sambalpur for his constant support.

Funding: No funding sources

Conflict of interest: None declared

Ethical approval: The study was approved by the Institutional Ethics Committee

\section{REFERENCES}

1. Perälä J, Suvisaari J, Saarni SI, Kuoppasalmi K, Isometsä E, Pirkola S, et al. Lifetime prevalence of psychotic and bipolar I disorders in a general population. Arch Gen Psychiatry. 2007;64:19-28.

2. Barch DM, Bustillo J, Gaebel W. Logic and justification for dimensional assessment of symptoms and related clinical phenomena in psychosis: relevance to DSM-5. Schizophr Res. 2013;150(1):15-20.

3. Kane JM. Strategies for improving compliance in treatment of schizophrenia by using a long - acting formulation of an antipsychotic: clinical studies. $\mathbf{J}$ Clin Psychiatry. 2003;64(16):34-40.

4. Tondan R. Bridging the Efficacy - Effectiveness Gap in the Antipsychotic Treatment of Schizophrenia: Back to the Basics. J Clin Psychiatry. 2014;75(11):1321-2.

5. Tandon R. Antipsychotics in the treatment of schizophrenia: an overview. J Clin Psychiatry. 2011;72(1):4-8.

6. Tandon R, Nasrallah HA, Keshvana MS. Schizophrenia, "just the facts" 5: treatment and prevention: past, present and future. Schizopher Res. 2010;122(1-3):1-23.

7. Kane J, Honigfeld G, Singer J, Meltzer H. Clozapine for the treatment- resistant schizophrenic: a double blind comparison of chlorpromazine. Arch Gen Psychiatry. 1988;45(9):789-96.

8. McEvoy JP, Lieberman JA, Stroup TS. CATIE investigators. Effectiveness of clozapine versus olanzapine, quetiaepine and risperidone in patients with chronic schizophrenia who did not respond to prior atypical antipsychotic treatment. Am J Psychiatry. 2006;163(4):600-10.
9. Guy W. Clinical global impressions. ECDEU Assessment Manual of Psychopharmacology Revised 1976. US Department of Health, Education, and Welfare; Rockville, MD; 1976: 217-222.

10. Cortesi PA, Mencacci C, Luigi F, Pirfo E, Berto P, Sturkenboom CJM, et al. Compliance, persistence, costs and quality of life in young patients treated with antipsychotic drugs: results from the COMETA study. BMC Psychiatry. 2013;13:244-471.

11. Grebb JA, Caroly SP, Sussman N, editors. Kaplan \& Sadock's Synopsis of Psychiatry: Behavioral Sciences/ Clinical psychiatry, 10th Edition. Lippincott Williams \& Wilkins; 2007: 469.

12. Diagnostic and Statistical Manual of Mental Disorders, 5th Edition. England: American Psychiatric Association; 2013. Available at: https://www.psychiatry.org/psychiatrists/practice/ds m. Accessed on 3 October 2019.

13. Johnson S, Sathyaseelan M, Charles H, Jeyaseelan V, Jacob KS. Insight, psychopathology, explanatory models and outcome of schizophrenia in India: a prospective 5- year cohort study. BMC Psychiatry. 2012;12:159.

14. Suresh KK, Kumar CN, Thirthalli J, Bijjal S, Venktesh BK. Work functioning of schizophrenia patients in a rural south Indian community: Status at 4- year follow up. Soc. Psychiatry Psychiatric Epidemiol. 2012;47:1865-71.

15. Kua J, Wong KE, Kua EH, Tsoi WF. A 20- year follow- up study on schizophrenia in Singapore. Acta Psychiatr Scand. 2003;108:118-25.

16. Liberman JA, Stroup TS, McEvoy JP, Swartz MS, Rosenheck RA, Perkins Do et al. Effectiveness of antipsychotic drugs in patients with chronic schizophrenia. N Eng J Med. 2005;353:1209-23.

17. Ravanic DB, Dejanovic SMD, Janjic V, Jovic SD, Milovanovic DR, Jakovljevic V et al. Effectiveness of clozapine, haloperidol and chlorpromazine in schizophrenia during a five- year period. Arq Neuropsiquiatr. 2009;67(2):195-202.

18. McCue RE, Waheed R, Charles R. Comparative effectiveness of second generation antipsychotics and haloperidol in acute schizophrenia. Br J Psychiatry. 2006;185:243-5.

19. Macfadden W, DeSouza C, Crivera C, Kozma CM, Dirani RD, Mao L. Assessment of effectiveness measures in patients with schizophrenia initiated on risperidone long- acting therapy: The SOURSE study results. BMC Psychiatry. 2011;11:167.

Cite this article as: Agrawal R, Rath B, Shukla RK, Mohapatra S. Effectiveness analysis of antipsychotics in schizophrenia using psychometric scales: an observational study. Int J Basic Clin Pharmacol 2020;9:305-9. 